\title{
Preconcentration of Cadmium in Environmental Samples by Cloud Point Extraction and Determination by FAAS
}

\author{
Catalina Bosch Ojeda, Fuensanta Sánchez Rojas*, José Manuel Cano Pavón \\ Department of Analytical Chemistry, Faculty of Sciences, University of Málaga, Málaga, Spain \\ E-mail: fsanchezr@uma.es \\ Received July 21, 2010; revised September 1, 2010; accepted September 3, 2010
}

\begin{abstract}
Cloud point extraction (CPE) has been used for the preconcentration of cadmium, after the formation of a complex with 1, 5-bis(di-2-pyridylmethylene) thiocarbonohydrazide (DPTH), and further determination by flame atomic absorption spectrometry (FAAS) using Triton X-114 as surfactant. The main factors affecting the CPE, such as concentration of Triton X-114 and DPTH, $\mathrm{pH}$, equilibration temperature and incubation time, were optimized for the best extract efficiency. Under the optimum conditions i.e., $\mathrm{pH} 5.4,[\mathrm{DPTH}]=$ $6 \times 10^{-3} \%$, [Triton X-114] $=0.25 \%(\mathrm{v} / \mathrm{v})$, an enhancement factor of 10.5 fold was reached. The lower limit of detection (LOD) obtained under the optimal conditions was $0.95 \mu \mathrm{g} \mathrm{L}^{-1}$. The precision for 8 replicate determinations at 20 and $100 \mu \mathrm{gL}^{-1} \mathrm{Cd}$ were $2.4 \%$ and $2 \%$ relative standard deviation (R.S.D.). The calibration graph using the preconcentration method was linear with a correlation coefficient of 0,998 at levels close to the detection limit up to at least $200 \mu \mathrm{gL}^{-1}$. The method was successfully applied to the determination of cadmium in water, environmental and food samples and in a BCR-176 standard reference material.
\end{abstract}

Keywords: Cadmium, Flame Atomic Absorption Spectrometry, Cloud Point Extraction, Triton X-114, Water Samples, Food Samples

\section{Introduction}

Monitoring the presence of toxic trace elements in diverse matrices is an extremely important task to evaluate occupational and environmental exposure. In this sense, cadmium is one of the most toxic elements and accumulates in humans mainly in the kidneys and liver and is classified as a prevalent toxic element with biological half-life in the range of 10-30 years [1]. One of the pathways that cadmium enters human body is through daily intake of food and water, thus the monitoring of cadmium concentrations in food and water samples is of significant importance. The maximum contaminant level allowed by the American Environmental Protection Agency (US EPA) in standard drinking water is $10 \mu \mathrm{g}$ $\mathrm{L}^{-1}$ to provide ample protection of human health.

Monitoring trace element concentrations in biological materials, particularly biological fluids, might be considered a difficult analytical task [2,3], mostly due to the complexity of the matrix and the low concentration of these elements, which requires sensitive instrumental techniques and often a preconcentration step. Concretely, spectrometric techniques for the analysis of trace cad- mium have developed rapidly due to the increasing need for accurate measurements at extremely low levels of this element in diverse matrices. An interesting revision presented by Ferreira et al. [4] covers separation and preconcentration procedures, and considers the features of the application with several spectrometric techniques.

In this way, CPE techniques exploit a peculiar property of most non-ionic surfactants that form micelles in aqueous solution: they become turbid when heated to the appropriate cloud point temperature. Above the cloud point temperature, the micellar solution separates into a small, surfactant rich phase and a larger diluted aqueous phase. In the aqueous phase, the surfactant concentration remains near the critical micelle concentration. Any analyte solubilised in the hydrophobic core of the micelle in the unheated solution, will be concentrated in the surfactant-rich phase following the cloud point extraction $[5,6]$.

Numerous reports have been published on the preconcentration of cadmium, alone or in mixtures, by CPE method prior to its determination using spectrometric techniques [7-34]. Table 1 lists recent works concerning with cadmium preconcentration by CPE and determination by spectrometric techniques. 
Table 1. Cadmium preconcentration by CPE.

\begin{tabular}{|c|c|c|c|c|}
\hline Matrix & Reagent/surfactant & Pre-concentration factor & Technique & Ref. \\
\hline Seawater & PAN & 120 & FAAS & 7 \\
\hline Waters & DDTP/Triton X-114 & 29 & ICP-MS & 8 \\
\hline Waters & TAN/Triton X-114 & 58 & FAAS & 9 \\
\hline Human hair & DDTP/Triton X-114 & 22 & FAAS & 10 \\
\hline Waste and waters & Dithizone/Triton X-114 & 52 & FAAS & 11 \\
\hline Seawater & DDTC/Triton X-114 & 52 & GFAAS & 12 \\
\hline $\begin{array}{l}\text { Physiological solution, mineral } \\
\text { and lake waters and tobacco }\end{array}$ & DDTP/Triton X-114 & - & FAAS & 13 \\
\hline Biological materials & DDTP/Triton X-114 & 129 & GFAAS & 14 \\
\hline Waters & PMBP/Triton X-100 & 23 & FAAS & 15 \\
\hline Waters & Iodide/Triton X-114 & 55.6 & FAAS & 16 \\
\hline Water and urine & APDC/Triton X-114 & 13 & TS-FF-AAS & 17 \\
\hline Waters & PONPE 7.5 & 62 & CV-AAS & 18 \\
\hline Waters & PAN/Triton X-100 & 50 & GFAAS & 19 \\
\hline Waters & 5-Br-PADAP/Triton X-114 & 21 & GFAAS & 20 \\
\hline $\begin{array}{l}\text { Water standard reference } \\
\text { material and urine }\end{array}$ & 5-Br-PADAP/PONPE 7.5 & 22 & GFAAS & 21 \\
\hline Urine & APDC/Triton X-114 & 15 & WCAAS & 22 \\
\hline Water and tobacco & GBHA/Triton $\mathrm{X}-114 / \mathrm{SDS} / \mathrm{NaCl}$ & 22 & GFAAS & 23 \\
\hline Waters & Carboxylic acids/OP-10 & - & FAAS & 24 \\
\hline Urine & DDTP/Triton X-114 & 16 & GFAAS & 25 \\
\hline Drinking waters & TAC/Triton X-114 & 22 & FS-FAAS & 26 \\
\hline Natural waters & DDTP/Triton X-114 & - & FAAS & 27 \\
\hline Waters & TAN/Triton X-114 & 20.3 & FAAS & 28 \\
\hline Natural waters & $\begin{array}{l}\text { Schiff base benzylbis thiosemicarbazone/ } \\
\text { Triton X-114 }\end{array}$ & 140 & FAAS & 29 \\
\hline $\begin{array}{l}\text { Mineral drinking water, river } \\
\text { water and seawater }\end{array}$ & NDDBH/Triton X-114 & 157 & FAAS & 30 \\
\hline Waters & PAR/Triton X-114 & 9.4 & ICP-OES & 31 \\
\hline Environmental samples & BIES/Triton X-114 & 48 & FAAS & 32 \\
\hline Waters & o-phen and eosin/PONPE 7.5 & - & Molecular fluorescence & 33 \\
\hline Rice and water & Dithizone/Triton X-114 & $\begin{array}{c}152 \\
93\end{array}$ & $\begin{array}{l}\text { W-coil ETV-AFS } \\
\text { W-coil GFAAS }\end{array}$ & 34 \\
\hline
\end{tabular}


In this work, we report on the results obtained in a study of the CPE of $\mathrm{Cd}^{2+}$, after the formation of a complex with DPTH using Triton X-114 as surfactant followed by analysis by FAAS.

\section{Experimental}

\subsection{Instrumentation}

A thermostated bath Model Selecta Precisterm, maintained at the desired temperature, was used for the CPE experiments. Phase separation was achieved with a centrifuge Selecta Centromix in $10 \mathrm{~mL}$ calibrated conical tubes.

A Varian Model SpectrAA 50 (Mulgrave, Victoria, Australia) flame atomic absorption spectrometer was used for the analysis with the appropriate cadmium hollow cathode lamp. The operating parameters were set as recommended by the manufacturer. Atomic absorption measurements were carried out in an air-acetylene flame. The following conditions were used: absorption line $\mathrm{Cd}$ : $228.8 \mathrm{~nm}$; slit widths: $0.5 \mathrm{~nm}$; and lamp currents: $4 \mathrm{~mA}$.

\subsection{Reagents and Samples}

High purity water (resistivity $18 \mathrm{M} \Omega \mathrm{cm}^{-1}$ ) obtained by a Milli-Q® water purification system (Millipore, Bedford, MA, USA) was used throughout this work. $1000 \mathrm{mg} \mathrm{L}^{-1}$ stock solutions of cadmium (E. Merck, Darmstadt, Germany). Working standard solution was obtained daily by stepwise dilution of the standard stock solution. DPTH solution in DMF was prepared by dissolving solid reagent samples prepared and purified by the authors. Non-ionic surfactant, Triton X-114 stock solution (2\%, $\mathrm{v} / \mathrm{v}$ ) was prepared by dissolving $2 \mathrm{~mL}$ of concentrated solution (Merck, Darmstadt, Germany) in $100 \mathrm{~mL}$ hot deionised water. These reagents were all of analytical grade or better.

The accuracy of the method for determination of cadmium content was checked by analyzing the reference standard material BCR 176 "City waste incineration ash"; for this the certified cadmium content was $470 \pm 9$ $\mathrm{mg} \mathrm{kg}{ }^{-1}$. The sample was first prepared in accordance with the instructions on the analysis certificate, after which an accurately weighed amount $(50 \mathrm{mg})$ was subjected to microwave digestion. The solution obtained was then adjusted to the optimum $\mathrm{pH}$ and, finally, the sample was diluted to $25 \mathrm{~mL}$ with de-ionized water in a calibrated flask.

The proposed method was also evaluated by analysis of cadmium in several spiked food samples. The $\mathrm{Cd}$ concentrations in all the original samples were below the detection limit. For this purpose, standard solutions con- taining cadmium were added to $0.2-0.5 \mathrm{~g}$ of diverse food and the resulting materials were mineralized by microwave digestion, adjusted $\mathrm{pH}$ and diluted at convenient volume.

Natural waters were collected in polypropylene bottles previously cleaned by soaking for $24 \mathrm{~h}$ in $10 \%(\mathrm{v} / \mathrm{v}) \mathrm{ni}-$ tric acid and finally rinsed thoroughly with ultrapure water before use.

\subsection{Procedure}

$10 \mathrm{~mL}$ analyte solution containing cadmium, $1 \mathrm{~mL}$ buffer solution $\mathrm{pH} 5.4$, DPTH $6 \times 10^{-3} \%$ and $0.25 \%(\mathrm{v} / \mathrm{v})$ Triton X-114 was kept in a thermostated bath at $50^{\circ} \mathrm{C}$ for 30 min. Phase separation was accelerated by centrifuging the resultant solution at $3800 \mathrm{rpm}$ for $5 \mathrm{~min}$. The conical tubes were then immersed in an ice-water mixture for 20 min, allowing ease of removing the supernatant bulk aqueous phase. A small volume of surfactant rich phase remained at the bottom of the tube. To decrease the viscosity of the extract and to facilitate sampling, $0.4 \mathrm{~mL}$ of $\mathrm{HNO}_{3} 0.1 \mathrm{M} / \mathrm{MeOH}$ was added to surfactant-rich phase. The cadmium content was determined by flame atomic absorption at $228.8 \mathrm{~nm}$ against a blank solution. Calibration was carried using different standard solutions of cadmium submitted to the same preconcentration and determination procedures. Blank solution was submitted to the same procedure and measured in parallel to the samples.

\section{Results and Discussion}

\subsection{Study of the CPE System Variables}

In the so-called cloud point extraction, several parameters play a substantial role in the performance and aggregation of the surfactant system, thus entrapping the analyte species. CPE of metal ions is known to depend on several factors such as type and amount of reagent and surfactant, $\mathrm{pH}$ of solution, ionic strength, equilibration temperature and time, etc. We have investigated the $\mathrm{CPE}$ process in order to obtain optimum conditions.

\subsubsection{Effect of $\mathbf{p H}$ and Triton $\mathrm{X}-114$ Concentration}

The formation of metal complexes and its chemical stability are the two important influence factors for the CPE, and the $\mathrm{pH}$ plays a unique role on metal chelate formation and subsequent extraction; in this sense, cadmium(II) react with DPTH to form intensely coloured complex and in a previous study, the characteristics of this chelate were described so cadmium(II) forms a complex with DPTH in a wide range of $\mathrm{pH}$.

$\mathrm{CPE}$ of cadmium was performed in solutions of $\mathrm{pH}$ 
ranging from 3.6 to 5.6. Separation of metal ions by cloud point method involves the prior formation of a complex with sufficient hydrophobicity to be extracted in to the small volume of surfactant-rich phase. Extraction recovery depends on the $\mathrm{pH}$ at which complex formation occurs.

On the other hand, in CPE, since the temperature corresponding to cloud point is correlated with the hydrophilic property of surfactants, an appropriate surfactant is important. The surfactants, which have too high or too low cloud point, are not suitable for the CPE separation/ preconcentration of trace elements. A successful cloud point extraction should maximize the extraction efficiency by minimizing the phase volume ratio (Vorg/Vaqueous), thus improving its concentration factor. Triton $\mathrm{X}-114$ was chosen for the formation of surfactant rich phase due to its recognized physicochemical characteristics: low cloud point temperature, high density of the surfactant rich phase; which facilitates phase separation by centrifugation, commercial availability, relatively low price and low toxicity.

These variables of interest in the CPE process were optimized with the aid of experimental design. The significant factors were optimized by using a factorial design $3^{2}$. The $\mathrm{pH}$ varied between 3.6 and 5.6, and the Triton X-114 concentration ranged from 0.1 to $0.4 \%$. The experimental results as absorbance are described in Ta- ble 2. The significance of the effects was checked by analysis of the variance (ANOVA) and using $P$-value significance levels. Also, the ANOVA results produced the graphs showing the influence of main effects represented in Figure 2, interaction plot in Figure $\mathbf{3}$ and standardized Pareto chart in Figure 4. These data were fitted into the following function:

Table 2. Factorial design for optimization of the experimental conditions.

\begin{tabular}{cccc}
\hline Experiment & Triton (\%) & $\mathrm{pH}$ & Absorbance \\
\hline 1 & 0.4 & 3.6 & 0.349 \\
2 & 0.1 & 5.6 & 0.517 \\
3 & 0.1 & 4.8 & 0.53 \\
4 & 0.4 & 4.8 & 0.471 \\
5 & 0.4 & 5.6 & 0.546 \\
6 & 0.2 & 5.6 & 0.485 \\
7 & 0.1 & 3.6 & 0.182 \\
8 & 0.2 & 3.6 & 0.325 \\
9 & 0.2 & 4.8 & 0.477 \\
\hline
\end{tabular}
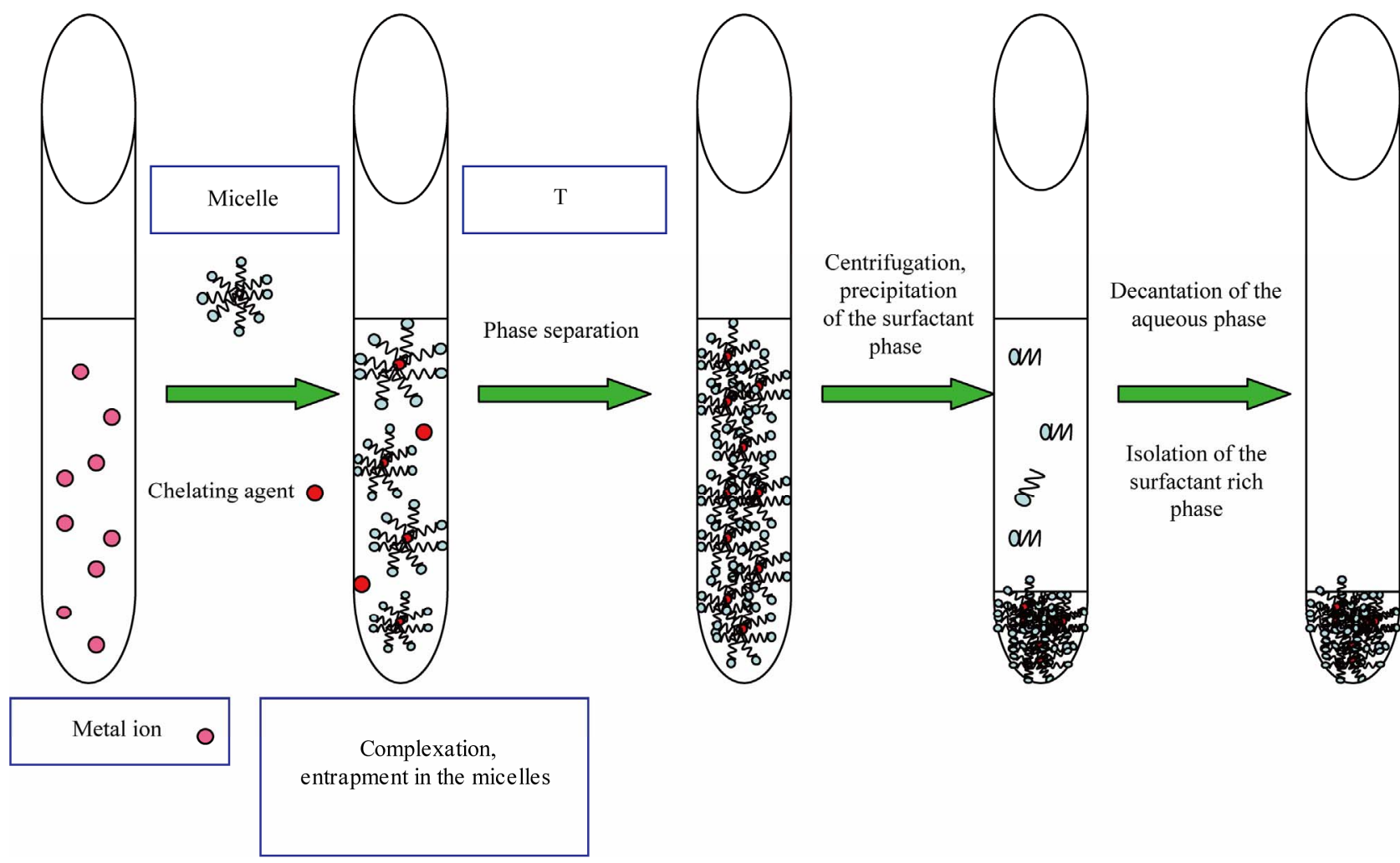

Figure 1. Scheme of the CPE procedure. 


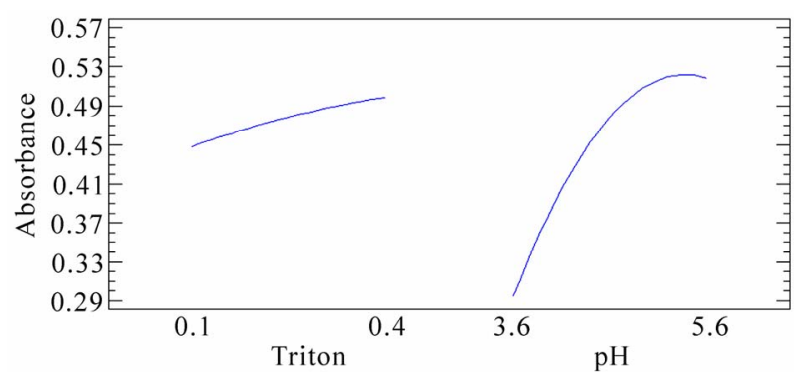

Figure 2. Influence of main effects on the absorbance.

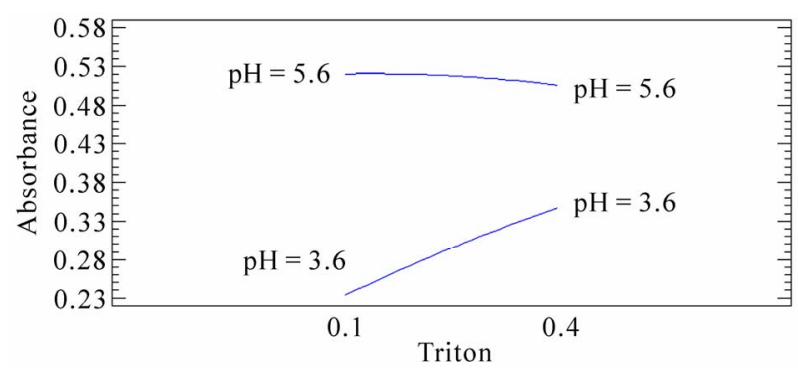

Figure 3. Interaction plots.

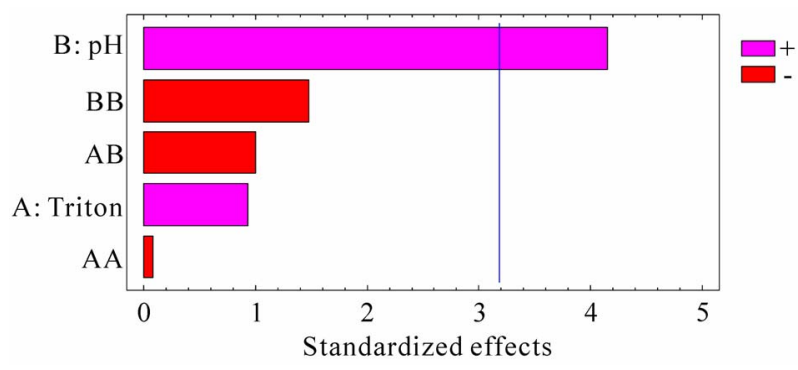

Figure 4. Pareto's chart.

Absorbance $=-1,85484+1,25039$ (Triton) $+0,825714$ $(\mathrm{pH})-0,205556$ (Triton) ${ }^{2}-0,213299$ (Triton) $(\mathrm{pH})-$ $0,0718056(\mathrm{pH})^{2}$

This equation shows a maximum condition of absorbance for a Triton X-114 concentration of $0.25 \%$ and $\mathrm{pH}$ 5.4 .

\subsubsection{Effect of DPTH Concentration}

The variation of the analytical signal as a function of the concentration of DPTH in the range of $5 \times 10^{-3}-2 \times$ $10^{-2} \%(\mathrm{w} / \mathrm{v})$ was studied, and the experimental results in Figure 5 demonstrated that the signal intensity of the analyte was accentuated by DPTH at concentrations up to about $6 \times 10^{-3} \%(\mathrm{w} / \mathrm{v})$. The maximum signal intensity achieved with this concentration remained practically constant up to the highest amount studied. A $6 \times 10^{-3} \%$ $(\mathrm{w} / \mathrm{v})$ DPTH was selected for further research.

\subsubsection{Effect of Ionic Strength}

The influence of ionic strength was examined by study-

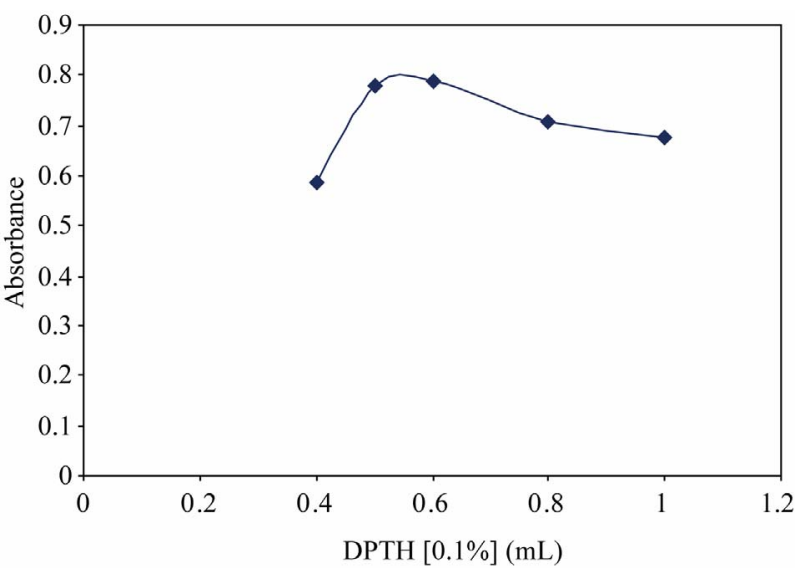

Figure 5. Influence of DPTH concentration.

ing the extraction efficiency for $\mathrm{NaCl}$ concentration in the range $0.5-3 \%$. Ionic strength had no significant effect upon percent recovery and sensitivity.

\subsubsection{Effects of the Equilibration Temperature and Time}

It is desirable to employ the shortest incubation time and the lowest possible equilibrium temperature, which comprise completion of the reaction and efficient separation of the phases. As mentioned above, after evaluating the incubation time in the range 10-40 min, it was kept for $30 \mathrm{~min}$, which is sufficient for the completion of the complex reaction and also for the clouding process. It was also observed that a temperature of $50^{\circ} \mathrm{C}$ is sufficient for maximum recovery of the cadmium.

In general, centrifugation time hardly ever affects micelle formation but accelerates phase separation in the same sense as in conventional separations of a precipitate from its original aqueous environment. Therefore, a centrifugation time of $5 \mathrm{~min}$ at $3800 \mathrm{rpm}$ was selected as optimum, since complete separation occurred for this time and no appreciable improvements were observed for long time.

In the phase separation step, the surfactant-rich phase with high viscosity was settled. The addition of a diluent, such as $0.4 \mathrm{~mL}$ of $\mathrm{HNO}_{3} 0.1 \mathrm{M} /$ methanol mixture reduces the surfactant phase viscosity and facilitates its transfer into the flame. The optimized conditions of CPE are summarized in Table 3 .

\subsection{Analytical Characteristics}

Table 4 summarizes the analytical characteristics of the optimized method, including regression equation determining before and after cloud point extraction method, linear range, limit of detection and reproducibility of $\mathrm{Cd}$ after CPE. The limit of detection, defined as $\mathrm{C}_{\mathrm{L}}=3 \mathrm{~S}_{\mathrm{B}} / \mathrm{m}$ 
Table 3. The optimized conditions for Cd determination using CPE method.

\begin{tabular}{lclc}
\hline \multicolumn{4}{c}{ Optimum CPE conditions } \\
\hline $\mathrm{pH}$ & 5.4 & Equilibrium temperature $\left({ }^{\circ} \mathrm{C}\right)$ & 50 \\
DPTH (\%) & $6 \times 10^{-3}$ & Equilibrium time (min) & 30 \\
Buffer: Acetic acid/Sodium acetate $(\mathrm{M})$ & 0.2 & Centrifuge time $(\mathrm{min})$ & 5 \\
Triton X-114 $(\%, \mathrm{v} / \mathrm{v})$ & 0.25 & Diluent $(\mathrm{mL}): \mathrm{HNO}_{3} 0.1 \mathrm{M} /$ methanol & 0.4 \\
\hline
\end{tabular}

Table 4. Analytical characteristics of the proposed method.

\begin{tabular}{|c|c|}
\hline Regression equation after $\mathrm{CPE}$ & $\mathrm{A}=0.0021[\mathrm{Cd}(\mathrm{II})]+0.0025 ; \mathrm{R}^{2}=0,9985$ \\
\hline Regression equation before $\mathrm{CPE}$ & $A=0.0002[C d(I I)]+0,0005 ; R^{2}=0,9906$ \\
\hline Linear range $\left(\mathrm{ng} \mathrm{mL}^{-1}\right)$ & $10-200$ \\
\hline Limit of detection ( $\left.\mathrm{ng} \mathrm{mL} \mathrm{L}^{-1}\right)$ & 0.95 \\
\hline Limit of determination $\left(\mathrm{ng} \mathrm{mL}^{-1}\right)$ & 4.3 \\
\hline Reproducibility (R.S.D.\%) $\mathrm{n}=8$ & $2.4,[\mathrm{Cd}(\mathrm{II})]=20 \mathrm{ng} \mathrm{mL}^{-1} ; 2.0,[\mathrm{Cd}(\mathrm{II})]=100 \mathrm{ng} \mathrm{mL}^{-1}$ \\
\hline Improvement factor & 10.5 \\
\hline
\end{tabular}

(where $\mathrm{CL}, \mathrm{S}_{\mathrm{B}}$, and $\mathrm{m}$ are the limit of detection, standard deviation of the blank, and slope of the calibration equation, respectively), was $0.95 \mathrm{ng} \mathrm{mL}^{-1}$. The improvement factor, defined as the slope ratio of the calibration graph of the CPE method to that of the calibration graph without preconcentration, was 10.5 .

\subsection{Effect of Foreign Ions}

The effects of representative potential interfering species were tested. To check these effects, a standard solution containing cadmium and other ions was prepared and cadmium was determined using the procedure proposed. The results obtained (Table 5) showed that at the tested concentrations, the other ions do not interfere in the procedure proposed.

\subsection{Applications}

In order to evaluate the analytical applicability of the proposed method, it was applied to the determination of cadmium in several samples.

A reference material (BCR-176 "City Waste Incineration Ash") certified for its content in cadmium was analyzed for method validation. Recovery experiments (Table 6) were conducted as well.

In view of the application of the method to the determination of cadmium in food samples, the ability to re- cover cadmium from different samples spiked with cadmium was investigated. All samples were arbitrarily selected and acquired from a local superstore. For this purpose, standard solutions containing different quantities of cadmium were added to samples and the resulting material was prepared as described under Experimental. Standard additions method was used in all instances and the results were obtained by extrapolation. The results of these analyses are summarised in Table 6, and indicated excellent recoveries in all instances.

In the laboratory, before the preconcentration procedure, all the water samples were filtered through a 0.45 $\mu \mathrm{m}$ pore-size membrane filter to remove suspended particulate matter and were stored at $4^{\circ} \mathrm{C}$. The optimized methodology was applied for the determination of $\mathrm{Cd}$ in different water samples and the analytical results along with the recovery are given in Table 6.

As can be seen, good recoveries were obtained in the spiked real samples analysis.

Table 5. Tolerance ratio of diverse ions on the determination of cadmium (100 $\left.\mathrm{ng} \mathrm{mL}^{-1}\right)$.

\begin{tabular}{cc}
\hline Ions & Tolerance ratio $(\mathrm{m} / \mathrm{m})$ \\
\hline $\mathrm{K}^{+}, \mathrm{I}^{-}, \mathrm{Pb}^{2+}, \mathrm{Mg}^{2+}, \mathrm{HCO}_{3}^{-}$, & $>100$ \\
$\mathrm{Ca}^{2+}, \mathrm{Cr}^{3+}, \mathrm{Al}^{3+}, \mathrm{Cu}^{2+}, \mathrm{Fe}^{3+}$, & 50 \\
$\mathrm{Mn}^{2+}, \mathrm{Ba}^{2+}, \mathrm{SO}_{4}^{+}, \mathrm{F}^{-}$ & \\
\hline
\end{tabular}


Table 6. Determination of cadmium in real samples.

\begin{tabular}{|c|c|c|c|}
\hline Sample & Added (ng $\left.\mathrm{mL}^{-1}\right)$ & Found $\left(\mathrm{ng} \mathrm{mL} L^{-1}\right)^{\mathrm{a}}$ & Recovery (\%) \\
\hline Tap water & 20 & $19.9 \pm 0.1$ & 99.5 \\
\hline \multirow[t]{2}{*}{ Sea water } & 20 & $21.3 \pm 1.0$ & 106.5 \\
\hline & 20 & $20.9 \pm 0.8$ & 104.5 \\
\hline \multirow[t]{3}{*}{ Certified sea water } & 40 & $39.3 \pm 0.8$ & 98.3 \\
\hline & 60 & $61.4 \pm 1.2$ & 102.3 \\
\hline & Added $\left(\mu \mathrm{g} \mathrm{g} \mathrm{g}^{-1}\right)$ & Found $\left(\mu \mathrm{g} \mathrm{g}^{-1}\right)$ & \\
\hline Apple & 2.46 & $2.45 \pm 0.29$ & 99.6 \\
\hline Lettuce & 4.88 & $4.94 \pm 0.5$ & 101.2 \\
\hline Liver & 3.98 & $3.68 \pm 0.52$ & 92.4 \\
\hline Chick-pea & 2.33 & $2.36 \pm 0.18$ & 101.3 \\
\hline Fish & 2.37 & $2.39 \pm 0.18$ & 100.8 \\
\hline Bignonia leaves & 4.17 & $4.18 \pm 0.8$ & 100.2 \\
\hline Pinus leaves & 4.47 & $4.33 \pm 0.5$ & 96.7 \\
\hline \multirow[t]{2}{*}{ Soil } & 5.23 & $5.63 \pm 0.4$ & 107.6 \\
\hline & $\begin{array}{l}\text { Certified value } \\
\quad\left(\mathrm{mg} \mathrm{kg}^{-1}\right)\end{array}$ & $\begin{array}{l}\text { Found value } \\
\left(\mathrm{mg} \mathrm{kg}^{-1}\right)\end{array}$ & \\
\hline BCR 176 & $470 \pm 9$ & $475 \pm 25$ & 101.1 \\
\hline
\end{tabular}

${ }^{\mathrm{a}}$ mean \pm standard deviation $(\mathrm{n}=3)$

\section{Conclusions}

The reagent DPTH was successfully employed in a CPE procedure for the determination of cadmium in environmental and food samples by FAAS. The method significantly inproved the performance of the FASS detection for cadmium. With the low cost and easily available accessories, the detectability of a traditional FAAS instrument can be comparable to that of more sophisticated instruments, such as ET-AAS. Also, CPE offers many advantages over traditional liquid-liquid extraction, such as elimination of handling large volumes of volatile, toxic and flamable organic solvents. The method has been validated by the analysis of standard reference material.

\section{Acknowledgements}

The authors thank to the Ministerio de Ciencia e Innovación for supporting this study (Projects CTQ200907858) and also the Junta de Andalucia.

\section{References}

[1] A. C. Davis, P. Wu, X. F. Zhang, X. D. Hou and B. T.
Jones, "Determination of Cadmium in Biological Samples," Applied Spectroscopy Reviews, Vol. 41, No. 1, 2006, pp. 35-75.

[2] S. Arce, S. Cerutti, R. Olsina, M. R. Gomez and L. D. Martinez, "Trace Element Profile of a Wild Edible Mushroom (Suillus Granulatus)," Journal of Association of Official Analytical Chemists International, Vol. 91, No. 4, 2008, pp. 853-857.

[3] M. W. Ashraf and S. Akram, "Physicochemical Characteristics and Heavy Metal Contents of Saudi Arabian Floral Honeys," Fresenius Environmental Bulletin, Vol. 17, No. 7b, 2008, pp. 877-881.

[4] S. L. C. Ferreira, J. B. Andrade, M. G. A. Korn, M. G. Pereira, V. A. Lemos, W. N. L. dos Santos, F. M. Rodrigues, A. S. Souza, H. S. Ferreira and E. G. P. da Silva, "Review of Procedures Involving Separation and Preconcentration for the Determination of Cadmium Using Spectrometric Techniques," Journal of Hazardous Materials, Vol. 145, No. 3, 2007, pp. 358-367.

[5] M. A. Bezerra, M. A. Z. Arruda and S. L. C. Ferreira, "Cloud Point Extraction as a Procedure of Separation and Préconcentration for Metals Determination Using Spectroanalytical Techniques: A Review," Applied Spectroscopy Reviews, Vol. 40, No. 4, 2005, pp. 269-299.

[6] C. B. Ojeda and F. S. Rojas, "Separation and Preconcentration by a Cloud Point Extraction Procedure for Determination of Metals: An Overview," Analytical and Bioanalytical Chemistry, Vol. 394, No. 3, 2009, pp. 759-782.

[7] C. G. Pinto, J. L. P. Pavón, B. M. Cordero and E. R. Beato, "Cloud Point Preconcentration and Flame Atomic Absorption Spectrometry: Application to the Determination of Cadmium," Journal of Analytical Atomic Spectrometry, Vol. 11, No. 1, 1996, pp. 37-41.

[8] M. A. M. da Silva, V. L. A. Frescura and A. J. Curtius, "Determination of Trace Elements in Water Samples by Ultrasonic Nebulization Inductively Coupled Plasma Mass Spectrometry after Cloud Point Extraction," Spectrochimica Acta B, Vol. 55, No. 7, 2000, pp. 803-813.

[9] J. Chen and K. C. Teo, "Determination of Cadmium, Copper, Lead and Zinc in Water Samples by Flame Atomic Absorption Spectrometry after Cloud Point Extraction," Analytica Chimica Acta, Vol. 450, No. 1, 2001, pp. 215-222.

[10] J. L. Manzoori and A. T. Bavili, "Cloud Point Preconcentration and Flame Atomic Absorption Spectrometric Determination of $\mathrm{Cd}$ and $\mathrm{Pb}$ in Human Hair," Analytica Chimica Acta, Vol. 470, No. 2, 2002, pp. 215-221.

[11] J. L. Manzoori and G. Karim-Nezhad, "Development of a Cloud Point Extraction and Preconcentration Method for $\mathrm{Cd}$ and Ni Prior to Flame Atomic Absorption Spectrometric Determination," Analytica Chimica Acta, Vol. 521, No. 2, 2004, pp. 173-177.

[12] C. G. Yuan, G. B. Jiang, Y. Q. Cai, B. He and J. F. Liu, "Determination of Cadmium at the Nanogram per Liter Level in Seawater by Graphite Furnace AAS Using Cloud Point Extraction," Atomic Spectroscopy, Vol. 25, No. 4, 2004, pp. 170-176.

[13] L. M. Coelho and M. A. Z. Arruda, "Preconcentration 
Procedure Using Cloud Point Extraction in the Presence of Electrolyte for Cadmium Determination by Flame Atomic Absorption Spectrometry," Spectrochimica Acta B, Vol. 60, No. 5, 2005, pp. 743-748.

[14] T. A. Maranhão, D. L. G. Borges, M. A. S. da Veiga and A. J. Curtius, "Cloud Point Extraction for the Determination of Cadmium and Lead in Biological Samples by Graphite Furnace Atomic Absorption Spectrometry," Spectrochimica Acta B, Vol. 60, No. 5, 2005, pp. 667-672.

[15] P. Liang, J. Li and X. Yang, "Cloud Point Extraction Preconcentration of Trace Cadmium as 1-Phenyl-3methyl-4-benzoyl-5-pyrazolone Complex and Determination by Flame Atomic Absorption Spectrometry," Microchimica Acta, Vol. 152, No. 1-2, 2005, pp. 47-51.

[16] A. Afkhami, T. Madrakian and H. Siampour, "Flame Atomic Absorption Spectrometric Determination of Trace Quantities of Cadmium in Water Simples after Cloud Point Extraction in Triton X-114 without Added Chelating Agents," Journal of Hazardous Materials, Vol. 138, 2006, pp. 269-272.

[17] P. Wu, Y. Zhang, Y. Lv and X. Hou, "Cloud Point Extraction-Thermospray Flame Quartz Furnace Atomic Absorption Spectrometry for Determination of Ultratrace Cadmium in Water and Urine," Spectrochimica Acta B, Vol. 61, No. 12, 2006, pp. 1310-1314.

[18] J. L. Manzoori, H. Abdolmohammad-Zadeh and M. Amjadi, "Ultratrace Determination of Cadmium by Cold Vapor Atomic Absorption Spectrometry after Preconcentration with a Simplified Cloud Point Extraction Methodology," Talanta, Vol. 71, No. 2, 2007, pp. 582-587.

[19] X. S. Zhu, X. H. Zhu and B. S. Wang, "Determination of Trace Cadmium in Water Samples by Graphite Furnace Atomic Absorption Spectrometry after Cloud Point Extraction," Microchimica Acta, Vol. 154, No. 1-2, 2006, pp. 95-100.

[20] S. Xiao, J. Chen, X. Wu and Y. Miao, "Determination of Cadmium in Water Samples by Graphite Furnace Atomic Absorption Spectrometry after Cloud Point Extraction," Journal of Analytical Chemistry, Vol. 62, No. 1, 2007, pp. $42-45$.

[21] P. R. Aranda, R. A. Gil, S. Moyano, I. De Vito and L. D. Martinez, "Cloud Point Extraction for Ultra-Trace Cd Determination in Microwave-Digested Biological Samples by ETAAS," Talanta, Vol. 77, No. 2, 2008, pp. 663-666.

[22] G. L. Donati, K. E. Pharr, C. P. Calloway Jr., J. A. Nóbrega and B. T. Jones, "Determination of Cd in Urine by Cloud Point Extraction-Tungsten Coil Atomic Absorption Spectrometry," Talanta, Vol. 76, No. 5, 2008, pp. 1252-1255.

[23] H. Filik, F. Dondurmacioglu and R. Apak, "Micelle Mediated Extraction of Cadmium from Water and Tobacco Samples with Glyoxal-bis(2-hydroxyanil) and Determination by Electrothermal Atomic Absorption Spectrometry," International Journal of Environmental Analytical Chemistry, Vol. 88, No. 9, 2008, pp. 637-648.

[24] V. A. Doroshchuk and S. A. Kulichenko, "Preconcentration of Cadmium with OP-10 Nonionic Surfactant Phases at the Cloud Point," Journal of Analytical Chemistry, Vol. 60, No. 5, 2005, pp. 400-403.
[25] T. D. A. Maranhão, E. Martendal, D. L. G. Borges, E. Carasek, B. Welz and A. J. Curtius, "Cloud Point Extraction for the Determination of Lead and Cadmium in Urine by Graphite Furnace Atomic Absorption Spectrometry with Multivariate Optimization Using Box-Behnken Design," Spectrochimica Acta B, Vol. 62, No. 9, 2007, pp. 1019-1027.

[26] L. A. Portugal, H. S. Ferreira, W. N. L. Santos and S. L. C. Ferreira, "Simultaneous Pre-Concentration Procedure for the Determination of Cadmium and Lead in Drinking Water Employing Sequential Multi-Element Flame Atomic Absorption Spectrometry," Microchemical Journal, Vol. 87, No. 1, 2007, pp. 77-80.

[27] S. M. Talebi, S. Habib-Ollahi and A. Semnani, "Cloud Point Extraction and Flame Atomic Absorption Spectrometric Determination of Lead and Cadmium in Natural Waters," Asian Journal of Chemistry, Vol. 19, 2007, pp. 2445-2451.

[28] E. L. Silva and P. dos S. Roldán, "Simultaneous Flow Injection Preconcentration of Lead and Cadmium Using Cloud Point Extraction and Determination by Atomic Absorption Spectrometry," Journal of Hazardous Materials, Vol. 161, No. 1, 2009, pp. 142-147.

[29] S. D. Abkenar, M. Hosseini and M. Salavati-Niasari, "Cloud Point Extraction and Preconcentration of Silver and Cadmium Using Schiff Base Prior to Flame Atomic Absorption Spectrometric Determination," Asian Journal of Chemistry, Vol. 20, No. 6, 2008, pp. 4291-4300.

[30] M. Arvand, A. Pourhabib, A. Afshari, M. Bagherinia, N. Ghodsi and R. J. Shemshadi, "Determination of Cadmium and Zinc in Water Samples by Flame Atomic Absorption Spectrometry after Cloud-Point Extraction," Journal of Analytical Chemistry, Vol. 63, No. 10, 2008, pp. 954-959.

[31] E. L. Silva, P. S. Roldan and M. F. Giné, "Simultaneous Preconcentration of Copper, Zinc, Cadmium, and Nickel in Water Samples by Cloud Point Extraction Using 4-(2Pyridylazo)-Resorcinol and Their Determination by Inductively Coupled Plasma Optic Emission Spectrometry," Journal of Hazardous Materials, Vol. 171, No. 1-3, 2009, pp. 1133-1138.

[32] M. Ghaedi, A. Shokrollahi, K. Niknam, E. Niknam, A. Najibi and M. Soylak, "Cloud Point Extraction and Flame Atomic Absorption Spectrometric Determination of Cadmium(II), Lead(II), Palladium(II) and Silver(I) in Environmental Samples," Journal of Hazardous Materials, Vol. 168, No. 2-3, 2009, pp. 1022-1027.

[33] M. C. Talio, M. O. Luconi, A. N. Masi and L. P. Fernández, "Determination of Cadmium at Ultra-Trace Level by CPE-Molecular Fluorescence Combined Methodology," Journal of Hazardous Materials, Vol. 170, No. 1, 2009, pp. 272-277.

[34] X. Wen, P. Wu, L. Chen and X. Hou, "Determination of Cadmium in Rice and Water by Tungsten Coil Electrothermal Vaporization-Atomic Fluorescence Spectrometry and Tungsten Coil Electrothermal Atomic Absorption Spectrometry after Cloud Point Extraction," Analytica Chimica Acta, Vol. 650, No. 1, 2009, pp. 33-38. 